\title{
H. pylori infection and extra-gastroduodenal diseases
}

Feng-Woei Tsay ${ }^{1,2}$ and Ping-I Hsu ${ }^{1 *}$

\begin{abstract}
Helicobacter pylori infection is the principal cause of peptic ulcer disease, gastric adenocarcinoma and gastric mucosa-associated lymphoid tissue lymphoma. Recent studies have shown that it may interfere with many biological processes and determine or influence the occurrence of many diseases outside the stomach. Currently, the role of $\mathrm{H}$. pylori in idiopathic thrombocytopenic purpura and iron deficiency anemia is well documented. Emerging evidence suggests that it may also contribute to vitamin B12 deficiency, insulin resistance, metabolic syndrome, diabetes mellitus and non-alcoholic liver disease. Additionally, it may increase the risk of acute coronary syndrome, cerebrovascular disease, neurodegenerative disease and other miscellaneous disorders. Different pathogenic mechanisms have been hypothesized, including the occurrence of molecular mimicry and the induction of a low-grade inflammation. This review summarizes the results of the most relevant studies on the extra-gastroduodenal manifestations of $\mathrm{H}$. pylori infection.
\end{abstract}

Keywords: Helicobacter pylori, Iron deficiency anemia, Idiopathic thrombocytopenic purpura and vitamin B12 deficiency

\section{Background}

Helicobacter pylori infection is the principal cause of chronic gastritis, gastric ulcer, duodenal ulcer, gastric adenocarcinoma and gastric mucosa-associated lymphoid tissue lymphoma $[1,2]$. In recent decades, many articles have published on the fascinating topic of extragastroduodenal manifestations of $H$. pylori infection, including hematological, metabolic, cardiovascular, neurodegenerative and allergic disorders [3-13]. Different pathogenic mechanisms have been hypothesized, including the occurrence of molecular mimicry and the induction of a low-grade inflammation. Indeed, $H$. pylori infection is a very good model for studying host-bacterial interactions and very attractive for those interested in the role of gut microbiota in health and diseases. Here, we summarize the results of the most relevant studies on the extragastroduodenal manifestations of $H$. pylori infection.

\footnotetext{
* Correspondence: williamhsup@yahoo.com.tw

${ }^{1}$ Division of Gastroenterology and Hepatology, Department of Internal Medicine, Kaohsiung Veterans General Hospital and National Yang-Ming University, 386 Ta Chung 1st Road, Kaohsiung 813, Taiwan, Republic of China Full list of author information is available at the end of the article
}

\section{Iron deficiency anemia}

The link between Iron deficiency anemia (IDA) and $H$. pylori infection was reported firstly in 1991 by Blecker et al., who cured IDA of a 15 year-old female presenting with anemia-related syncope and $H$. pylori-induced chronic active hemorrhagic gastritis by eradication therapy without iron supplements [14]. The association of $H$. pylori infection with unexplained IDA has been proven in adult and pediatric populations $[15,16]$ though a few investigations didn't show this link [17, 18]. Recently, Qu et al. conducted a meta-analysis of 15 case-control studies to investigate the relation between $H$. pylori infection and IDA [19]. H. pylori infection was diagnosed by endoscopy and histological examination in five studies, in which patients with peptic ulcer disease and gastric cancer were not included. The other 10 studies confirmed H. pylori infection by serology or urea breath test. The data showed an increased risk of IDA in patients with $H$. pylori infection with an odds ratio (OR) of 2.2 (95\% confidence interval [CI]:1.5-3.2) [19]. Several works also demonstrated recovery from IDA by successful eradication of H. pylori without iron supplements [20]. Yuan et al. performed a meta-analysis of 16 randomized controlled trials involving 956 patients to assess the

(C) The Author(s). 2018 Open Access This article is distributed under the terms of the Creative Commons Attribution 4.0 International License (http://creativecommons.org/licenses/by/4.0/), which permits unrestricted use, distribution, and 
impact of $H$. pylori eradication therapy on IDA [21]. In this work, the diagnosis of $H$. pylori infection was based on rapid urease test or histology in eight studies, in which patients with peptic ulcer disease were excluded. The other eight studies confirmed $H$. pylori infection by urea breath test. The follow-up time in these studies ranged from 1 to 3 months. The difference from baseline to endpoint of hemoglobin, serum iron, and serum ferritin in the meta-analysis was statistically significantly different between anti-H. pylori treatment plus oral iron and oral iron alone (differences: $\mathrm{Hb}, 1.48 \mathrm{~g} / \mathrm{dL}$; serum iron: $1.15 \mathrm{~mol} / \mathrm{L}$; serum ferritin, $1.84 \mathrm{ng} / \mathrm{mL}$ ) [21].

H. pylori causes IDA by several mechanisms. First, increased iron loss can be due to hemorrhagic gastritis, peptic ulcer disease and gastric adenocarcinoma [22] Second, CagA protein of $H$. pylori has been shown to participate in iron acquisition from interstitial holotransferrin [23]. Iron uptake by $H$. pylori is enhanced during the growth of the bacteria [24]. Third, $H$. pylori-related corporal gastritis may decrease acid secretion due to gland atrophy and results in the reduction of iron absorption from diet [25].

In summary, the association of $H$. pylori and IDA has been conclusively proven in numerous studies. Current international and national guidelines recommend eradication of $H$. pylori infection in patients with unexplained IDA [26, 27].

\section{Immune thrombocytopenic purpura}

Gasbarrini et al. reported the first case of $H$. pylori infection associated with immune thrombocytopenic purpura (ITP) in 1998 [28]. An observation study from Japan also found a good platelet response in ITP patients treated by $H$. pylori eradication [29]. A randomized controlled trial by Brito et al. revealed that $H$. pylori eradication resulted in a significant platelet response in children and adolescents affected by ITP [30]. The role of $H$. pylori infection in ITP has also been confirmed by several other studies [31, 32]. Nonetheless, some studies from countries with low prevalence of infection, like France and the United States, did not find the link between $H$. pylori infection and ITP [33, 34]. Recently, Stasi et al. conducted a meta-analysis of 25 studies to investigate the impact of anti-H. pylori therapy on ITP [34]. The assessing time for platelet response ranged from one to six months. The data showed that the rates of complete response (platelet count $\geqq 100 \times 10^{9} / \mathrm{L}$ ) and overall response (platelet count $\geqq 30 \times 10^{9} / \mathrm{L}$ and at least doubling of the basal count) after successful eradication of $H$. pylori were 42.7 and $50.3 \%$, respectively [35]. The predictors of a good response to eradication therapy were countries with higher prevalence of $H$. pylori infection (such as Japan and Italy) and patients with milder degree of thrombocytopenia [35]. In the majority of ITP patients responding to anti- $H$. pylori therapy, the durability of platelet response is more than 7 years, indicating the disease is cured [36]. Another meta-analysis by Arnold et al. performed a meta-analysis to determine the effect of $H$. pylori eradication therapy in patients with ITP by comparing the platelet response in ITP patients with and without $H$. pylori infection [37]. The odds of achieving a platelet count response following eradication therapy were 14.5 higher (95\% CI: 4.2 to 83.0) in patients with $H$. pylori infection than in those without infection (response rate: $51.2 \%$ vs. $8.8 \%$ ). These findings strengthen the causal association between $H$. pylori infection and ITP. Several mechanisms regarding H. pylori-associated ITP have been proposed [38]. One intriguing hypothesis concerning molecular mimicry is that cross-reactive antibodies are produced that react both $H$. pylori components and platelet surface antigens. Takahashi et al. showed that platelet elutes from $H$. pylori-infected ITP patients recognized CagA protein in immunoblots, but those from $H$. pylori-infected non-ITP patients did not [39]. Bai et al. also reported that monoclonal antibodies generated against $H$. pylori urease $\mathrm{B}$ react with GP IIb/IIIa expressed on the platelet surface [40]. While these findings suggest molecular mimicry between $H$. pylori components and platelet surface antigens, the exact pathogenic roles of these cross-reactive antibodies remain obscure. In another potential mechanism, H. pylori infection may alter $\mathrm{Fc} \gamma$ receptor balance of moncytes/macrophages and induce autoantibody formation. A recent study showed that the FcyR II B expression on circulating monocytes was down-regulated in H. pylori-infected ITP patients [41]. Therefore, H. pylori may alter $\mathrm{Fc} \gamma$ receptor balance of moncytes/macrophages through downregulation of the inhibitory receptor Fc $\gamma$ R II B.

In conclusion, many studies support the association between $H$. pylori infection and ITP. Current international and national guidelines recommend that $H$. pylori infection should be sought and treated in patients with ITP [27].

\section{Vitamin B12 deficiency}

The link between vitamin B12 deficiency and $H$. pylori infection was reported firstly in 1984 by O'Connor et al. who showed Campylobacter-like organisms in patients with type A gastritis and pernicious anemia [42]. Studies have demonstrated a link between chronic H. pylori infection and malabsorption of vitamin B12 [43]. Sarari et al. showed that vitamin B12 deficiency was present in $67.4 \%(29 / 43)$ of the patients with $H$. pylori infection [44]. Shuval-Sudai et al. found a higher prevalence of $H$. pylori infection in patients at the lower end of the normal range of serum vitamin B12 levels [45]. However, most studies regarding the association between vitamin B12 and $H$. pylori infection focus on testing $H$. pylori 
status and measuring serum levels of vitamin B12. No adequate interventional studies proving the effect of anti-H. pylori therapy on vitamin B12 deficiency exist.

\section{Metabolic syndrome and diabetes mellitus (DM)}

Many epidemiological studies have supported a link between insulin resistance, metabolic syndrome and $H$. pylori infection $[46,47]$. Chen et al. demonstrated that $H$. pylori-infected subjects had a higher prevalence of metabolic syndrome than those without $H$. pylori infection [48]. Additionally, Yang et al. showed a significant association between $H$. pylori infection and DM [49]. Similar results were also observed by other investigators [50]. Furthermore, Horikawa et al. revealed that $H$. pylori infection worsened glycemia control in diabetic patients [51]. Polyzos et al. conducted a systemic review including nine studies and showed a trend toward a positive association between $H$. pylori infection and insulin resistance [47]. In contrast, several studies did not find the link between $H$. pylori infection and insulin resistance or metabolic syndrome [52]. Naja et al. showed no association between $H$. pylori infection and metabolic syndrome in a Lebanese population [53]. A meta-analysis of 18 studies found no strong correlation between $H$. pylori infection and serum concentrations of total cholesterol and triglyceride [54]. Wada et al. also found that successful eradication of $H$. pylori could not improve glucose control of DM in Japanese patients [55]. Furthermore, a recent randomized controlled trial involving $49 \mathrm{H}$. pylori-infected subjects in a prediabetes stage showed that $H$. pylori eradication resulted in an increased Homeostatic model assessment of insulin resistance (HOMA-IR) [56].

Several studies reported a reverse link between $H$. pylori infection and obesity [57-60]. A case-control study from Taiwan demonstrated an inverse relationship between morbid obesity and $H$. pylori seropositivity [57]. An ecological study also showed an inverse correlation between $H$. pylori prevalence and rate of overweight/ obesity in countries of the developed world [58]. However, a large case-control study including 8820 participants from China showed body mass index was significantly and positively associated with $H$. pylori infection [59]. An intervention trial demonstrated serum ghrelin concentrations were inversely related to the severity of $H$. pylori-associated gastritis in prepubertal children [60]. Eradication of $H$. pylori infection resulted in a significant increase in body mass index along with a significant decrease in circulating ghrelin levels and an increase in leptin levels [60].

In summary, the issue of the association between $H$. pylori infection and metabolic syndrome or DM remains contradictory.

\section{Nonalcoholic fatty liver disease (NAFLD)}

A cohort study by Kim et al. demonstrated that the subjects with $H$. pylori infection had a higher incidence of NAFLD than those without infection (hazard ratio: 1.21 [95\% CI: 1.1-1.3]) [61]. Polyzos et al. also revealed that patients with NAFLD had higher anti- $H$. pylori IgG titers, together with lower circulating adiponectin and higher tumor necrosis factor- $\alpha$ levels, compared to non-NAFLD subjects [62]. However, opposite results from Korea and Japan showed no association between $H$. pylori infection and NAFLD $[63,64]$. Recently, a meta-analysis demonstrated a significantly increased risk of NAFLD in patients with $H$. pylori infection [65]. Nonetheless, the mechanism underlying the association between $H$. pylori infection and NAFLD remains unclear, and interventional studies proving the effect of anti- $H$. pylori therapy on NAFLD are fairly limited.

In summary, the association between $H$. pylori infection and NAFLD remains contradictory.

\section{Coronary artery disease (CAD)}

Mendall et al. first showed a link between $H$. pylori and CAD in 1994 [66]. Several studies reported that CagA-postive strains of $H$. pylori were associated with atherosclerosis [67-69]. Al-Ghamdi et al found that $H$. pylori plays an important role in the development of CAD by altering the lipid profile and enhancement of chronic inflammation [70]. Figura et al. also revealed that CagA-postive strains of $H$. pylori were associated with high serum levels of interleukin-6 and B-type natriuretic peptide in patients with CAD [71]. A nationwide retrospective cohort study demonstrated that $H$. pylori infection increased the risk of acute coronary syndrome [72]. In addition, a meta-analysis of 26 studies involving more than 20,000 patients also showed a significant association between $H$. pylori infection and the risk of myocardial infarction (OR: 2.10; 95\% CI: 1.8-2.5) [73]. However some studies from Indian and German did not find the association between $H$. pylori and CAD [74, 75]. Additionally, there are still no interventional studies proving the beneficial effect of $H$. pylori eradication in decreasing the incidence of CAD.

There are several proposed mechanisms underlying the association between $H$. pylori infection and CAD. $H$. pylori has been detected in human carotid atherosclerotic plaques [76]. Oshima et al. demonstrated the association of $H$. pylori infection with systemic inflammation and endothelial dysfunction in healthy male subjects [77]. They proposed that $H$. pylori infection may cause atherogenesis through persistent low-grade inflammation. Recently, molecular mimicry between CagA antigen of $H$. pylori and atherosclerotic plaque peptides has also been proposed as a possible mechanism [78]. 
In conclusion, there is controversial evidence linking H. pylori infection and CAD. No adequate interventional trials demonstrating a lower incidence of CAD as a result of anti- $H$. pylori therapy exit.

\section{Cerebrovascular disease}

Wincup et al. first reported a link between $H$. pylori infection and stroke in 1996 (OR $=1.57,95 \%$ CI 0.95 to 2.60) [79]. A Mexican study found that levels of antibodies to $H$. pylori predict incident stroke in fully adjusted models (OR: 1.58; 95\% CI: 1.1 to 2.3) [80]. Recently, Wang et al. performed a meta-analysis of 4041 Chinese patients, and found an association between $H$. pylori infection and non-cardioembolic stroke [81]. However, a cohort study of 9895 cases from the United States found a reverse link between $H$. pylori infection and stroke mortality, and this reverse association was stronger for $H$. pylori cagA positivity [82]. In summary, there is controversial evidence linking $H$. pylori infection and cerebrovascular disease.

\section{Other miscellaneous disorders}

Some studies also disclosed the relationship of $H$. pylori with dementia and Alzheimer's disease (AD) [83, 84]. A study in Greece by Kountouras et al. found higher prevalence of $H$. pylori infection in patients with $\mathrm{AD}$ than in the control group [85]. Hung et al. designed a study for the relationship between $H$. pylori infection and non-Alzheimer's dementia (non-AD) using a nationwide population-based dataset in Taiwan, and found that patients with $H$. pylori infection were 1.6-fold more likely to develop non-AD than those without infection [83]. A retrospective cohort study using nationwide database in Taiwan showed that eradication of $H$. pylori was associated with a decreased progression of dementia as compared to no eradication of H. pylori in AD patients with peptic ulcers [86]. However, further prospective randomized control trials are needed to clarify these findings.

The inverse relationship between $H$. pylori infection and allergic asthma has been reported. A meta-analysis by Zhou et al... in 2013 found lower prevalence rate of H. pylori infection in patients with allergic asthma [87]. Higher prevalence rate of $H$. pylori infection has been found in cirrhotic patients with hepatoencephalopathy than in those without hepatoencephalopathy [88]. Jaing et al also showed the association of $H$. pylori infection with elevated blood ammonia levels in cirrhotic patients

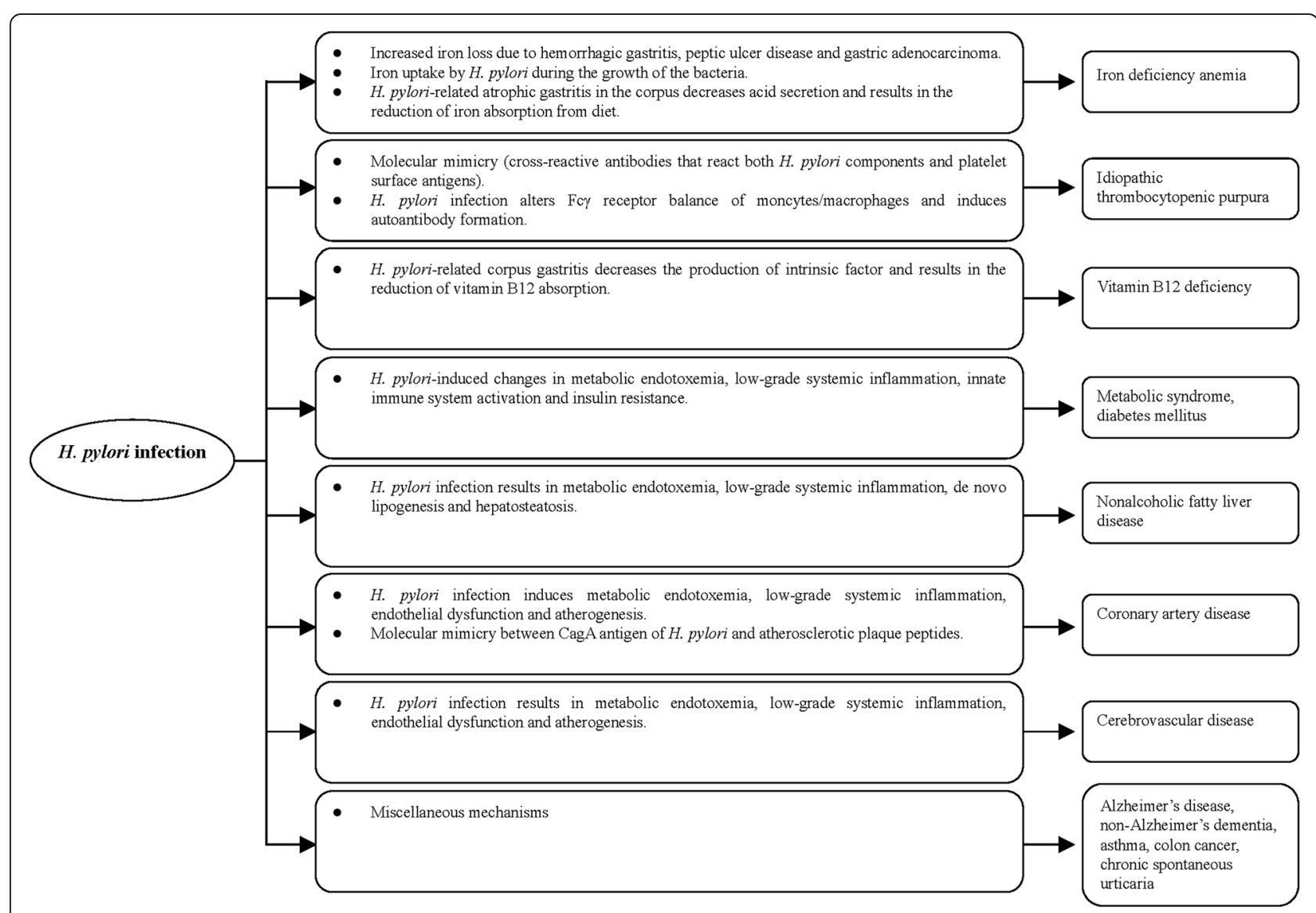

Fig. 1 The possible mechanism for the association between H. pylori infection and extra-gasroduodenal diseases 
Table 1 The relevant studies on the associations between H. pylori infection and extra-gastroduodenal diseases

\begin{tabular}{ll}
\hline Extra-gastroduodenal disease & Key evidences \\
\hline 1 Iron deficiency anemia (IDA) & Pros: \\
& 1. Qu et al. [19]: an increased risk of IDA in patients with \\
H. pylori infection (meta-analysis of case-control studies). & 2. Yuan et al. [21]: Eradication of H. pylori could improve \\
& the levels of hemoglobin and serum ferritin in patients \\
& with IDA (meta-analysis of intervention trials). \\
Cons: & \\
1. Sandstrom et al. [18]: no association between H. pylori \\
infection and IDA in female adolescents (case-control \\
study).
\end{tabular}

2 Immune thrombocytopenic purpura (ITP)

3 Vitamin B12 deficiency

4 Metabolic syndrome and diabetes mellitus (DM)

5 Nonalcoholic fatty liver disease (NAFLD)

6

\footnotetext{
Coronary artery disease (CAD)
}

\section{Pros:}

1. Stasi et al. [35]: The overall response rate of increased platelet count was $50.3 \%$ after successful eradication of H. pylori in ITP patients (meta-analysis of intervention trials).

2. Arnold et al. [37]: The odds of achieving a platelet count response following eradication therapy were 14.5 higher in ITP patients with $H$. pylori infection than in those without infection (response rate: $51.2 \%$ vs. $8.8 \%$ ) (meta-analysis of intervention trials).

Cons:

1. Michel et al. [34]: Seroprevalence of H. pylori in patients with ITP was not significantly different from that in control subjects (case-control study).

Pros:

1. Sarari et al. [44]: There was significant association between the presence of $H$. pylori infection and vitamin B12 deficiency (case-control study).

2. Shuval-Sudai et al. [45]: Prevalence of H. pylori with borderline (>145-180 pg/mL) or low normal (> 180-250 pg/mL) vitamin B12 levels than among those with vitamin B12>250 pg/mL (case-control study).

Pros:

1. Chen et al. [48]: H. pylori-infected subjects had a higher prevalence of metabolic syndrome than those without H. pylori infection (case-control study).

2. Yang et al. [49]: H. pylori infection was associated with risk of DM (case-control study).

Cons:

1. Naja et al. [53]: no association between H. pylori infection and metabolic syndrome (case-control study).

2. Wada et al. [55]: The eradication of Helicobacter pylori does not affect glycemic control in Japanese subjects with type 2 diabetes (intervention trial).

Pros:

1. Kim et al. [61]: The subjects with H. pylori infection had a higher incidence of NAFLD than those without infection (cohort study).

2. Wijarnpreecha et al. [65]: a significantly increased risk of NAFLD in patients with $\mathrm{H}$. pylori infection (meta-analysis of case-control studies).

Cons:

1. Okushin et al. [63]: no association between H. pylori infection and NAFLD (case-control study).

Pros:

1. Yu et al. [73]: significant association between H. pylori infection and the risk of myocardial infarction (meta-analysis of case-control studies).

Cons:

1. Schottker et al. [75]: no association between H. pylori infection and the risk of CAD (cohort study). seropositivity was significantly higher among subjects

\section{Conclusion}

Eradication of H. pylori infection is

recommended for patients with unexplained IDA.

H. pylori infection should be sought and treated in patients with ITP.

H. pylori infection is associated with vitamin B12 deficiency.

The association between $H$. pylori infection and metabolic syndrome or DM is contradictory.

The association between $H$. pylori infection and NAFLD remains contradictory.

The association between $H$. pylori infection and CAD is contradictory. 
Table 1 The relevant studies on the associations between H. pylori infection and extra-gastroduodenal diseases (Continued)

\begin{tabular}{|c|c|c|c|}
\hline & Extra-gastroduodenal disease & Key evidences & Conclusion \\
\hline$\overline{7}$ & Cerebrovascular disease & $\begin{array}{l}\text { Pros: } \\
\text { 1. Wang et al. [81]: significant association between H. pylori } \\
\text { infection and non-cardioembolic stroke (meta-analysis of } \\
\text { case-control studies). } \\
\text { Cons: } \\
\text { 1. Chen et al. [82]: a reverse link between H. pylori infection } \\
\text { and stroke mortality (cohort study). }\end{array}$ & $\begin{array}{l}\text { There is controversial evidence } \\
\text { linking H. pylori infection and } \\
\text { cerebrovascular disease. }\end{array}$ \\
\hline
\end{tabular}

[89]. Several studies have also reported that $H$. pylori infection increases the risk of colon adenocarcinoma and adenoma [90-92]. Recently, an association between H. pylori infection and chronic spontaneous urticaria has been reported but remains controversial. Fukuda et al. demonstrated a significant improvement of chronic spontaneous urticaria by anti-H. pylori therapy in Japanese patients [93]. This work was consistent with a systemic review of 10 studies by Federman et al. [94]. However, Moreira et al. did not find the association between $H$. pylori infection and chronic spontaneous urticaria [95].

In summary, there are still controversial evidences linking $H$. pylori infection and aforementioned miscellaneous disorders. Adequate interventional trials are needed to clarify these associations.

\section{Conclusions}

Recent studies have shown that $H$. pylori may interfere with many biological processes and determine or influence the occurrence of many diseases outside the stomach (Table 1 and Fig. 1). Currently, its role in ITP and IDA is well documented. Emerging evidence suggests that it may also contribute to vitamin B12 deficiency, insulin resistance, metabolic syndrome, diabetes mellitus and non-alcoholic liver disease. Additionally, it may also increase the risk of acute coronary syndrome, cerebrovascular disease, and neurodegenerative disease, $H$. pylori infection is a perfect model for the study of interplay between human beings and bacteria. Further studies are mandatory to clarify the pathogenesis of extragastroduodenal diseases induced by $H$. pylori infection.

\section{Abbreviations}

AD: Alzheimer's disease; Cl: Confidence interval; DM: Diabetes mellitus; IDA: Iron deficiency anemia; ITP: Immune thrombocytopenic purpura; NAFLD: Nonalcoholic fatty liver disease; OR: Odds ratio

\section{Authors' contributions}

Drs. PIH and FWT reviewed the articles and wrote the manuscript. Both authors read and approved the final manuscript.

Ethics approval and consent to participate

Not applicable.

Consent for publication

Not applicable.
Competing interests

The authors declare that they have no competing interests.

\section{Publisher's Note}

Springer Nature remains neutral with regard to jurisdictional claims in published maps and institutional affiliations.

\section{Author details}

${ }^{1}$ Division of Gastroenterology and Hepatology, Department of Internal Medicine, Kaohsiung Veterans General Hospital and National Yang-Ming University, 386 Ta Chung 1st Road, Kaohsiung 813, Taiwan, Republic of China. ${ }^{2}$ Cheng Shiu University, Kaohsiung, Taiwan, Republic of China.

Received: 4 May 2018 Accepted: 24 August 2018

Published online: 29 August 2018

References

1. Suerbaum S, Michetti P. Helicobacter pylori infection. N Engl J Med. 2002;347(15):1175-86.

2. Graham DY. Helicobacter pylori update: gastric cancer, reliable therapy, and possible benefits. Gastroenterology. 2015;148(4):719-31.

3. Realdi G, Dore MP, Fastame L. Extradigestive manifestations of helicobacter pylori infection: fact and fiction. Dig Dis Sci. 1999:44(2):229-36.

4. Suzuki H, Franceschi F, Nishizawa T, et al. Extragastric manifestations of helicobacter pylori infection. Helicobacter. 2011;16(Suppl 1):65-9.

5. Banic M, Franceschi F, Babic Z, et al. Extragastric manifestations of helicobacter pylori infection. Helicobacter. 2012:17(Suppl 1):49-55.

6. Deng B, Li Y, Zhang Y, et al. Helicobacter pylori infection and lung cancer: a review of an emerging hypothesis. Carcinogenesis. 2013;34(6):1189-95.

7. Papagiannakis $P$, Michalopoulos C, Papalexi F, et al. The role of helicobacter pylori infection in hematological disorders. Eur J Intern Med. 2013:24(8):685-90.

8. Buzas GM. Metabolic consequences of helicobacter pylori infection and eradication. World J Gastroenterol. 2014;20(18):5226-34.

9. Campuzano-Maya G. Hematologic manifestations of helicobacter pylori infection. World J Gastroenterol. 2014;20(36):12818-38.

10. Franceschi F, Tortora A, Gasbarrini G, et al. Helicobacter pylori and extragastric diseases. Helicobacter. 2014;19(Suppl 1):52-8.

11. Franceschi F, Zuccala G, Roccarina D, et al. Clinical effects of helicobacter pylori outside the stomach. Nat Rev Gastroenterol Hepatol. 2014;11(4):234-42

12. Wong F, Rayner-Hartley E, Byrne MF. Extraintestinal manifestations of helicobacter pylori: a concise review. World J Gastroenterol. 2014;20(34):11950-61.

13. Chmiela M, Gajewski A, Rudnicka K. Helicobacter pylori vs coronary heart disease - searching for connections. World J Cardiol. 2015;7(4):187-203.

14. Blecker U, Renders F, Lanciers $S$, et al. Syncopes leading to the diagnosis of a helicobacter pylori positive chronic active haemorrhagic gastritis. Eur J Pediatr. 1991;150(8):560-1.

15. Ortiz M, Rosado-Carrion B, Bredy R. Role of helicobacter pylori infection in Hispanic patients with anemia. Bol Asso Med P R. 2014;106:13-8.

16. Sato $Y$, Yoneyama $O$, Azumaya $M$, et al. The relationship between iron deficiency in patients with helicobacter pylori-infected nodular gastritis and the serum prohepcidin level. Helicobacter. 2015:20:11-8.

17. Bazmamoun $H$, Razavi Z, Esfahani $H$, et al. Evaluation of iron deficiency anemia and BMI in children suffering from helicobacter pylori infection. Iran J Ped Hematol Oncol. 2014;4:167-71.

18. Sandstrom G, Rodjer S, Kaijser B, et al. Helicobacter pylori antibodies and iron deficiency in female adolescents. PLoS One. 2014;9:e113059. 
19. Qu XH, Huang $X L$, Xiong $P$, et al. Does helicobacter pylori infection play a role in iron deficiency anemia? A meta-analysis World J Gastroenterol. 2010;16(7):886-96.

20. Annibale B, Marginani M, Monarca B, et al. Reversal of iron deficiency anemia after helicobacter pylori eradication in patients with asymptomatic gastritis. Ann Intern Med. 1999;131:668-72.

21. Yuan W, Li Y, Yang K, et al. Iron deficiency anemia in helicobacter pylori infection: meta-analysis of randomized controlled trials. Scand J Gastroenterol. 2010;45(6):665-76.

22. Tan HJ, Goh KL. Extragastrointestinal manifestations of Helicobacter pylori infection: facts or myth? A critical review. J Dig Dis. 2012;13:342-9.

23. Boyanova L. Role of helicobacter pylori virulence factors for iron acquisition from gastric epithelial cells of the host and impact on bacterial colonization. Future Microbiol. 2011;6(8):843-6.

24. Muhsen $\mathrm{K}$, Cohen D. Helicobacter pylori infection and iron stores: a systemic review and meta-analysis. Helicobacter. 2008;13:323-40.

25. Capurso G, Lahner E, Marcheggiano A, et al. Involvement of the corporal mucosa and related changes in gastric acid secretion characterize patients with iron deficiency anaemia associated with helicobacter pylori infection. Aliment Pharmacol Ther. 2001;15:1753-61.

26. Goddard AF, James MW, Mclntyre AS, et al. Guidelines for the management of iron deficiency anemia. Gut. 2011;60:1309-16.

27. Malfertheiner P, Megraud F, O'Morain CA, et al. Management of Helicobacter pylori infection--the Maastricht IV/ Florence consensus report. Gut. 2012;61(5):646-64.

28. Gasbarrini A, Franceschi F, Tartaglione R, et al. Regression of autoimmune thrombocytopenia after eradication of helicobacter pylori. Lancet. 1998;352(9131):878.

29. Kikuchi T, Kobayashi T, Yamashita T, et al. Eight-year follow-up of patients with immune thrombocytopenic purpura related toH. Pyloriinfection. Platelets. 2011;22(1):61-4.

30. Brito HS, Braga JA, Loggetto SR, et al. Helicobacter pylori infection and immune thrombocytopenia purpura in children and adolescents: a randomized controlled trial. Platelet. 2014;15:1-6.

31. Kim H, Lee WS, Lee KH, et al. Efficacy of helicobacter pylori eradication for the 1st-line treatment of immune thrombocytopenia patients with moderate thrombocytopenia. AnnHematol. 2015;94:939-46.

32. Noonavath RN, Lakshmi CP, Dutta TK, et al. Helicobacter pylori eradication in patients with chronic immune thrombocytopenic purpura. World J Gastroenterol. 2014;20:6918-23.

33. Michel M, Cooper N, Jean C, et al. Does helicobacter pylori initiate or perpetuate immune thrombocytopenic purpura? Blood. 2004;103(3):890-6.

34. Michel M, Khellaf M, Desforges $L$, et al. Autoimmune thrombocytopenic purpura and helicobacter pylori infection. Arch Intern Med. 2002;162(9):1033-6.

35. Stasi R, Sarpatwari A, Segal JB, et al. Effects of eradication of helicobacter pylori infection in patients with immune thrombocytopenic purpura: a systematic review. Blood. 2009;113(6):1231-40.

36. Tsumoto $\mathrm{C}$, Tominaga $\mathrm{K}$, Okazaki $\mathrm{H}$, et al. Long-term efficacy of helicobacter pylori eradication in patients with idiopathic thrombocytopenia purpura: 7-year follow-up prospective study. Ann Hematol. 2009;88:789-93.

37. Arnold DM, Bernotas A, Nazi l, et al. Platelet count response to H. Pylori treatment in patients with immune thrombocytopenic purpura with and without $\mathrm{H}$. Pylori infection: a systematic review. Haematologica. 2009:94(6):850-6.

38. Kuwana M. Helicobacter pylori-associated immune thrombocytopenia: clinical features and pathogenic mechanisms. World J Gastroenterol. 2014;20:714-23.

39. Takahashi T, Yujiri T, Shinohara K, et al. Molecular mimicry by helicobacter pylori CagA protein may be involved in the pathogenesis of H. Pyloriassociated chronic idiopathic thrombocytopenic purpura. Br J Haematol. 2004;124:91-6.

40. Bai $Y$, Wang $Z$, Bai $X$, et al. Cross reaction of antibody against helicobacter pylori urease B with platelet glycoprotein IIla and its significance in the pathogenesis of immune thrombocytopenic purpura. Int J Hematol. 2009;89:142-9.

41. Wu Z, Zhou J, Prsoon P, et al. Low expression of FCCRIIB in macrophages of immune thrombocytopenia-affected individuals. Int J Hematol. 2012;96:588-93.

42. O'Connor HJ, Axon AT, Dixon MF. Campylobacter-like organisms unusual in type a (pernicious anaemia) gastritis. Lancet. 1984;2(8411):1091.
43. Stabler SP. Vitamin B12 deficiency. N Engl J Med. 2013;368:2041-2.

44. Sarari AS, Farraj MA, Hamoudi W, et al. Helicobacter pylori, a causative agent of vitamin B12 deficiency. J Infect Dev Ctries. 2008;2(5):346-9.

45. Shuval-Sudai O, Granot E. An association between helicobacter pylori infection and serum vitamin B12 levels in healthy adults. J Clin Gastroenterol. 2003:36(2):130-3.

46. Eshraghian A, Hashemi SA, Hamidian Jahromi A, et al. Helicobacter pylori infection as a risk factor for insulin resistance. Dig Dis Sci. 2009:54(9):1966-70.

47. Polyzos SA, Kountouras J, Zavos C, et al. The association between helicobacter pylori infection and insulin resistance: a systematic review. Helicobacter. 2011;16(2):79-88

48. Chen TP, Hung HF, Chen MK, et al. Helicobacter pylori infection is positively associated with metabolic syndrome in Taiwanese adults: a cross-sectional study. Helicobacter. 2015;20:184-91

49. Yang GH, Wu JS, Yang YC, et al. Gastric helicobacter pylori infection associated with risk of diabetes mellitus, but not prediabetes. J Gastroenterol Hepatol. 2014;29:1794-9.

50. Bajai S, Rekwal L, Misra SP, et al. Association of Helicobacter pylori infection in patients with type 2 diabetes. Indian J Endocrinol Metab. 2014;18:694-9.

51. Horikawa C, Kodama S, Fujihara K, et al. High risk of failing eradication of helicobacter pylori in patients with diabetes: a meta-analysis. Diabetes Res Clin Pract. 2014;106:81-7.

52. Gillum RF. Infection with helicobacter pylori, coronary heart disease, cardiovascular risk factors, and systemic inflammation: the third National Health and nutrition examination survey. J Natl Med Assoc. 2004;96:1470-6.

53. Naja F, Nasreddine L, Hwalla $N$, et al. Association of $H$. Pylori infection with insulin resistance and metabolic syndrome among Lebanese adults. Helicobacter. 2012;17(6):444-51.

54. Danesh J, Peto R. Risk factors for coronary heart disease and infection with helicobacter pylori: meta-analysis of 18 studies. BMJ. 1998;316:1130-2.

55. Wada $Y$, Hamamoto $Y$, Kawasaki $Y$, et al. The eradication of helicobacter pylori does not affect glycemic control in Japanese subjects with type 2 diabetes. Jpn Clin Med. 2013:4:41-3.

56. Kachuei A, Amini M, Sebghatollahi V, et al. Effect of helicobacter pylori eradication on insulin resistance among prediabetic patients: a pilot study and single-blind randomized controlled clinical trial. J Res Med Sci. 2016;21:8

57. Wu MS, Lee WJ, Wang HH, et al. A case-control study of association of helicobacter pylori infection with morbid obesity in Taiwan. Arch Intern Med. 2005;165:1552-5.

58. Lender N, Talley NJ, Enck P, et al. Associations between helicobacter pylori and obesity--an ecological study. Aliment Pharmacol Ther. 2014:40:24-31.

59. Xu C, Yan M, Sun Y, et al. Prevalence of helicobacter pylori infection and its relation with body mass index in a Chinese population. Helicobacter. 2014;19:437-42.

60. Pacifico L, Anania C, Osborn JF, et al. Long-term effects of helicobacter pylori eradication on circulating ghrelin and leptin concentrations and body composition in prepubertal children. Eur J Endocrinol. 2008;158:323-32.

61. Kim TJ, Sinn DH, Min YW, et al. A cohort study on helicobacter pylori infection associated with non-alcoholic fatty liver disease. J Gastroenterol. 2017:52(11):1201-10

62. Polyzos SA, Kountouras J, Papatheodorou A, et al. Helicobacter pylori infection in patients with nonalcoholic fatty liver disease. Metabolism. 2013;62:121-6

63. Okushin $\mathrm{K}$, Takahashi $\mathrm{Y}$, Yamamichi $\mathrm{N}$, et al. Helicobacter pylori infection is not associated with fatty liver disease including non-alcoholic fatty liver disease: a large-scale cross-sectional study in Japan. BMC Gastroenterol. 2015;15:25.

64. Tang DM, Kumar S. The association between helicobacter pylori infection and nonalcoholic liver disease. Curr Gastroenterol Rep. 2017;19:5.

65. Wijarnpreecha K, Thongprayoon C, Panjawatanan P, et al. Helicobacter pylori and risk of nonalcoholic fatty liver disease: a systemic review and meta-analysis. J Gastroenerol. 2017; Jan 17; https://doi.org/10.1097/MCG. 0000000000000784

66. Mendall MA, Goggin PM, Molineaux N, et al. Relation of helicobacter pylori infection and coronary heart disease. Br Heart J. 1994;71(5):437-9.

67. Mayr M, Kiechl S, Mendall MA, Willeit J, Wick G, Xu QB. Increased risk of atherosclerosis is confined to CagA-positive Helicobacter pylori strains prospective results from the Bruneck study. Stroke. 2003;34:610-5.

68. Park MJ, Choi SH, Kim D, et al. Association between helicobacter pylori Seropositivity and the coronary artery calcium score in a screening population. Gut Liver. 2011;5(3):321-7. 
69. Huang B, Chen Y, Xie Q, et al. CagA-positive helicobacter pylori strains enhanced coronary atherosclerosis by increasing serum OxLDL and HsCRP in patients with coronary heart disease. Dig Dis Sci. 2011;56(1):109-14.

70. Al-Ghamdi A, Jiman-Fatani AA, El-Banna H. Role of chlamydia pneumoniae, helicobacter pylori and cytomegalovirus in coronary artery disease. Pak J Pharm Sci. 2011:24(2):95-101.

71. Figura N, Palazzuoli A, Vaira D, et al. Cross-sectional study: CagA-positive helicobacter pylori infection, acute coronary artery disease and systemic levels of B-type natriuretic peptide. J Clin Pathol. 2014;67(3):251-7.

72. Lai $C Y$, Yang TY, Lin CL, et al. Helicobacter pylori infection and the risk of acute coronary syndrome: a nationwide retrospective cohort study. Eur J Clin Microbiol Infect Dis. 2015;34:69-74.

73. Yu XJ, Yang X, Feng L, et al. Association between helicobacter pylor infection and angiographically demonstrated coronary artery disease: a meta-analysis. Exp Ther Med. 2017;13:787-93.

74. Padmavati S, Gupta U, Agarwal HK. Chronic infections \& coronary artery disease with special reference to Chalmydia pneumoniae. Indian J Med Res. 2012;135(2):228-32.

75. Schottker B, Adamu MA, Weck MN, et al. Helicobacter pylori infection, chronic atrophic gastritis and major cardiovascular events: a populationbased cohort study. Atherosclerosis. 2012;220(2):569-74.

76. Ameriso SF, Fridman EA, Leiguarda RC, et al. Detection of helicobacter pylori in human carotid atherosclerotic plaques. Stroke. 2001:32:385-91.

77. Oshima T, Ozono R, Yano Y, et al. Association of Helicobacter pylori infection with systemic inflammation and endothelial dysfunction in healthy male subjects. J Am Coll Cardiol. 2005;45:1219-22.

78. Kucukazman M, Yavuz B, Sacikara M, et al. The relationship between updated Sydney system score and LDL cholesterol levels in patients infected with helicobacter pylori. Dig Dis Sci. 2009;54:604-7.

79. Whincup PH, Mendall MA, Perry IJ, et al. Prospective relations between helicobacter pylori infection, coronary heart disease, and stroke in middle aged men. Heart. 1996;75(6):568-72

80. Sealy-Jefferson S, Gillespie BW, Aiello AE, et al. Antibody levels to persistent pathogens and incident stroke in Mexican Americans. PLoS One. 2013;8(6):e65959.

81. Wang ZW, Li Y, Huang LY, et al. Helicobacter pylori infection contributes to high risk of ischemic stroke: evidence from a meta-analysis. J Neurol. 2012;259(12):2527-37.

82. Chen Y, Segers S, Blaser MJ. Association between helicobacter pylori and mortality in the NHANES III study. Gut. 2013;62(9):1262-9.

83. Huang WS, Yang TY, Shen WC, et al. Association between helicobacter pylori infection and dementia. J Clin Neurosci. 2014;21(8):1355-8.

84. Honjo K, van Reekum R, Verhoeff NP. Alzheimer's disease and infection: do infectious agents contribute to progression of Alzheimer's disease? Alzheimers Dement. 2009;5(4):348-60.

85. Kountouras J, Tsolaki M, Gavalas E, et al. Relationship between helicobacter pylori infection and Alzheimer disease. Neurology. 2006;66(6):938-40.

86. Chang YP, Chiu GF, Kuo FC, et al. Eradication of helicobacter pylori is associated with the progression of dementia: a population-based study. Gastroenterol Res Pract. 2013;2013:175729.

87. Zhou X, Wu J, Zhang G. Association between helicobacter pylori and asthma: a meta-analysis. Eur J Gastroenterol Hepatol. 2013;25(4):460-8.

88. Hu BL, Wang HY, Yang GY. Association of Helicobacter pylori infection with hepatic encephalopathy risk: a systematic review. Clin Res Hepatol Gastroenterol. 2013;37(6):619-25.

89. Jiang HX, Qin SY, Min ZG, et al. Association of Helicobacter pylori with elevated blood ammonia levels in cirrhotic patients: a meta-analysis. Yonsei Med J. 2013;54(4):832-8.

90. Zhang Y, Hoffmeister M, Weck MN, et al. Helicobacter pylori infection and colorectal cancer risk: evidence from a large population-based case-control study in Germany. Am J Epidemiol. 2012:175(5):441-50.

91. Wu Q, Yang ZP, Xu P, et al. Association between helicobacter pylori infection and the risk of colorectal neoplasia: a systematic review and meta-analysis. Color Dis. 2013;15(7):e352-64.

92. Chen YS, Xu SX, Ding YB, et al. Helicobacter pylori infection and the risk of colorectal adenoma and adenocarcinoma: an updated meta-analysis of different testing methods. Asian Pac J Cancer Prev. 2013;14(12):7613-9.

93. Fukuda S, Shimoyama T, Umegaki T, et al. Effect of helicobacter pylori eradication in the treatment of Japanese patients with chronic idiopathic urticaria. J Gastroenterol. 2004:39(9):827-30.
94. Federman DG, Kirsner RS, Moriarty JP, et al. The effect of antibiotic therapy for patients infected with helicobacter pylori who have chronic urticaria. J Am Acad Dermatol. 2003:49(5):861-4.

95. Moreira A, Rodrigues J, Delgado L, et al. Is helicobacter pylori infection associated with chronic idiopathic urticaria? Allergol Immunopathol (Madr). 2003;31(4):209-14.

\section{Ready to submit your research? Choose BMC and benefit from:}

- fast, convenient online submission

- thorough peer review by experienced researchers in your field

- rapid publication on acceptance

- support for research data, including large and complex data types

- gold Open Access which fosters wider collaboration and increased citations

- maximum visibility for your research: over $100 \mathrm{M}$ website views per year

At $\mathrm{BMC}$, research is always in progress.

Learn more biomedcentral.com/submissions 